During the past months, there have been major developments in the PAGES office and the PAGES project.

\section{PAGES Project:}

The busy summer was fully focused on the PAGES 2nd Open Science Meeting, which was held in Beijing from 1012 August. A short report on this very successful meeting can be found on page 26 of this issue.

At the meeting, a plenary discussion on the future of PAGES provided direct feedback from scientists from the international paleo-community. Subsequently, the PAGES Scientific Steering Committee, together with the IPO, began to prepare a revised science plan, which will culminate in the submission of a new proposal to PAGES funding agencies (Swiss and US NSF) by the end of the year. Details are open for discussion amongst the PAGES community. Please visit our website (www.pages-igbp.org) to read about the proposed changes and add your comments. We invite you to participate in the process of defining PAGES scientific scope for the future. Your expertise and input is required to ensure that PAGES is well positioned to successfully serve paleoscientific research over the coming years.

\section{PAGES Office:}

The PAGES office experienced a change in staff last month, when Selma Ghoneim, PAGES Finance Manager, whom many of you will know, left to take up a position in the private sector. PAGES benefited greatly from her knowledge on how best to manage the sometimes complex financial needs of scientists, projects and the PAGES program as a whole. Her competence and cheerful smile will be missed. In her place, we are happy to welcome Michelle Kaufmann (www.pages-igbp.org/people/staff/kaufmann.html), who in only a short time has already integrated into the PAGES team.

In addition to organisational changes, you may have noticed that we have launched a new-look website. As well as a new design, the structure has also been somewhat changed. These modifications, based on feedback from many people, were introduced in the hope of improving site navigation and overall ease of use. The website overhaul is not yet complete. Things to look out for in the coming months include online forms for the submission of calendar and job entries, and easier access to your personal record and the PAGES Product Database.

\section{Newsletter:}

After this joint PAGES / CLIVAR issue, PAGES News will return to its usual format. The spring 2006 special issue will highlight ice core research but will also have an open section for workshop reports, program news and science highlights. We encourage you to continue to submit to the newsletter and take advantage of the fact that every special issue now also includes an open section for your contributions. The next deadline for submissions is 30 April 2006. Guidelines can be found at:

www.pages-igbp.org/products/newsletters/instructions

\title{
LOTRED-SA Long-Term climate REconstruction and Dynamics of (southern) South America: A collaborative, high-resolution multi-proxy approach
}

\section{Ricardo Villalba ${ }^{1}$ and Martin Grosjean²}

IIANIGLA-CRICYT, Mendoza, Argentina; ricardo@lab.cricyt.edu.ar ${ }^{2}$ NCCR Climate, Bern, Switzerland; grosjean@giub.unibe.ch

A small group of scientists from various disciplines gathered in Mendoza, Argentina (8-9 October 2005) to set up the organizational framework for the new PAGES Research Initiative LOTRED-(southern) South America (PAGES News Vol. 13 No. 2). Guidelines for collaboration, contributions and formats are available at www.pages-igbp. org/science/initiatives/lotred-sa.

The scientific goals were specified as (i) to collate, maintain and share a common state-of-the-art protected database (for contributors only) with available high-resolution multiproxy data sets for the last 500-2,000 years, (ii) to produce, as a collective of authors, a series of research results and papers that exceed the capacity of individuals within the group, and (iii) to compare multi-proxy reconstruction with results from GCM runs for the last ca. 2,000 years or selected windows of interest.

There are good reasons to contribute: It is increasingly within the policy of funding agencies that supported projects make their results and data sets available. You benefit from co-authorship of important contributions, your work is cited and made public. Original data sets remain protected (if you wish), only metadata will be published. The results are expected to achieve wide recognition, thus funding agencies might be interested in evaluating who contributed and which types of archives serve best for climate reconstructions.

Contributing with sets of original data to a database is a very sensitive issue and will be handled with the utmost care. The data policy of IGBP and principles and guidelines of ICSU will apply.

A first science meeting will be held in Mendoza, Argentina from 4-7 October 2006. The state of research and data sets will be presented and discussed. 